\title{
EFFICACY OF ORAL CLONIDINE AS A PRE-ANAESTHETIC MEDICATION ON THE ANAESTHESIA PROVIDED BY INTRATHECAL BUPIVACAINE WITH FENTANYL
}

\author{
Sridharan Srinivasan'1, Kumar Kandasamy²
}

${ }_{1}^{1}$ Assistant Professor, Department of Anaesthesiology, Government Tiruvannamalai Medical College Hospital. ${ }^{2}$ Associate Professor, Department of Anaesthesiology, Government Tiruvannamalai Medical College Hospital.

\begin{tabular}{l}
\hline ABSTRACT \\
BACKGROUND \\
nurgical trauma is real and severe tissue damage and pain following surgery is a universal phenomenon. Intrathecally administered \\
pain is the predominant feature. Oral clonidine premedication provides preoperative and intraoperative sedation, anxiolysis with \\
intraoperative haemodynamic stability.
\end{tabular}

\section{MATERIALS AND METHODS}

Efficacy of oral clonidine as a pre-anaesthetic medication on the anaesthesia provided by intrathecal bupivacaine with fentanyl. In this study, lumbar subarachnoid injection of hyperbaric bupivacaine $0.5 \%$ (15 mg) was given to 120 patients randomly divided into 4 groups (30 each), who had undergone vaginal hysterectomies; 30 patients were given oral placebo premedication with spinal bupivacaine (Group B), 30 patients were given oral placebo premedication and intrathecal fentanyl 10 ug with bupivacaine (Group FB), 30 patients were given oral clonidine 150 ug 90 minutes before subarachnoid block with spinal bupivacaine (Group CB) and another 30 patients were given oral clonidine 150 ug and intrathecal fentanyl 10 ug with bupivacaine (Group CFB).

\section{RESULTS}

Oral clonidine premedication prolonged the duration of both sensory $(274+40.4$ mins. vs $184.9+18.1$ mins. in Group B) and motor blockade $(122.8+21.3$ mins. vs $96.5+13.2$ mins. in Group B) of bupivacaine. Highest dermatomal levels were achieved with intrathecal fentanyl. Like clonidine, fentanyl itself prolonged the duration of sensory (274.5 + 28.3 mins.) and motor blockade (109 +20.0 mins.) of bupivacaine. The combination of clonidine and fentanyl with bupivacaine very significantly prolonged the duration of both motor blockade $(125.4+18.7$ mins. $)$ and the total duration of analgesia $(357+35.4$ mins. $)$. The complications associated with clonidine were hypotension, bradycardia and sedation. The complications with fentanyl were nausea, vomiting and pruritus. There was no increased severity of adverse effects with oral clonidine added to intrathecal fentanyl.

\section{CONCLUSION}

This study concludes the combination of oral clonidine and intrathecal fentanyl with bupivacaine increased the intraoperative analgesic efficacy and significantly prolonged the postoperative analgesia.

\section{KEYWORDS}

Clonidine, Fentanyl, Spinal Bupivacaine, Alpha 2 Agonist.

HOW TO CITE THIS ARTICLE: Srinivasan S, Kandasamy K. Efficacy of oral clonidine as a pre-anaesthetic medication on the anaesthesia provided by intrathecal bupivacaine with fentanyl. J. Evolution Med. Dent. Sci. 2016;5(98):7158-7161, DOI: 10. $14260 /$ jemds/2016/1620

\section{BACKGROUND}

This study was done after getting approval from Ethical Committee and informed consent of the patients and conducted in the period from Feb 2015 to Oct 2015. Clonidine, an imidazole compound, was synthesised in the early 1960's. It is a selective agonist for alpha-2 receptor with a ratio of 200 : 1 (alpha-2: alpha-1) and it is a partial agonist. It is rapidly and almost completely absorbed after oral administration and its bioavailability is nearly $100 \%$. Peak plasma concentration is reached within 60 - 90 mins. and maximal hypotensive effects are observed in $1-3 \mathrm{hrs}$. after an oral dose.

Financial or Other, Competing Interest: None.

Submission 29-09-2016, Peer Review 25-11-2016,

Acceptance 01-12-2016, Published 07-12-2016.

Corresponding Author:

Dr. Sridharan Srinivasan,

\#19, Mathalangulam Street,

Thiruvannamalai-606601,

Tamilnadu.

E-mail: sshospital2011@gmail.com

DOI: $10.14260 /$ jemds/2016/1620
The half-life of clonidine is between 6 to $24 \mathrm{hrs}$. and approximately $50 \%$ of the drug is metabolised in the liver to inactive metabolites, while the rest is excreted unchanged by the kidney. It acts on locus coeruleus major site for the hypnotic action of the alpha- 2 agonists. High densities of alpha-2 agonist binding sites have been observed in the dorsal motor nucleus of vagus nerve, which may be the site of the bradycardia and hypotensive effects of the alpha- 2 agonists. Potent analgesic by itself and act synergistically; clonidine and opioids mediate the analgesic action through independent receptors. Clonidine inhibits noradrenaline release from the peripheral nerve ending and this property in part contributes to the bradycardia effect of this agent. Clonidine has been documented to release Endothelial Derived Relaxant Factor (EDRF) in coronary artery and to enhance coronary blood flow induced by endogenous and exogenous adenosine. Clonidine potentiate the anaesthetic action of other agent, in particular narcotics and local anaesthetics and to reduce anaesthetic requirements during surgery. 


\section{MATERIALS AND METHODS}

This is a prospective double-blinded, randomised, placebocontrolled study; 120 patients who were posted for elective gynaecological surgeries (vaginal hysterectomy) were chosen at random. All of them belonged to ASA I and ASA II, age ranging between 24 and 70 years. Patients who had spinal deformities, bleeding disorders, local skin sepsis and chronic pulmonary diseases were excluded from the study. Informed consent was obtained after explaining the procedure in detail. Pre-anaesthetic assessment was done to exclude any local or systemic diseases, which might interface with the anaesthesia. Baseline measurement of pulse rate, respiratory rate, blood pressure and $\mathrm{SpO} 2$ were done. Patients were explained about the ten points Visual Analogue Pain Scale (VAPS).

Patients were randomised in a double-blinded fashion to one of four groups. Group B, FB, CB and CFB. In this study lumbar subarachnoid injection of hyperbaric bupivacaine $0.5 \%$ (15 mg) was given to 120 patients who had undergone vaginal hysterectomies; 30 patients were given oral placebo premedication with spinal bupivacaine (Group B), 30 patients were given oral placebo premedication and intrathecal fentanyl 10 ug with bupivacaine (Group FB), 30 patients were given oral clonidine 150 ug 90 minutes before subarachnoid block with spinal bupivacaine (Group CB) and another 30 patients were given oral clonidine $150 \mathrm{ug}$ and intrathecal fentanyl 10 ug with bupivacaine (Group CFB).

After explaining the procedure, patients were placed in the right lateral position. After thorough aseptic precautions in L3L4 interspinous space using a 23-G Quincke point spinal needle, subarachnoid puncture was done through midline approach. After ensuring free flow of cerebrospinal fluid total volume of subarachnoid injection was $3.2 \mathrm{~mL}$ in all the four groups. Patients were immediately returned to the supine position after completion of the subarachnoid block. Mean Arterial Pressure (MAP), respiratory rate, pulse rate and SpO2 were monitored every two minutes for the first 20 minutes, then every 10 minutes in the operating room and every 30 minutes in the postoperative recovery room and in the postoperative ward.

\section{Sensory Blockade}

The onset of highest dermatomal level and the duration of the sensory block were assessed by pinprick method every 30 seconds for the first 10 minutes and then every 10 minutes after subarachnoid block. The time from the intrathecal injection to the highest sensory level, regression of sensory level by two-segments from the highest sensory level, regression of sensory level by two segments from the highest sensory level were recorded.

VAPS and Quality of Analgesia (Visual Analog Pain Scale) Duration of absolute pain free period was defined as the time from the intrathecal injection to the perception of mild pain (VAPS $=0-1)$.

\section{The Onset and Duration of Grade 3 Motor Block}

It was assessed every 30 secs. for the first 10 minutes and then every 10 minutes after subarachnoid block by Bromage grading. Respiratory rhythm and rate were observed every 10 minutes in the operating room and every 30 minutes in the postoperative room.

\section{Blood Pressure and Pulse Rate}

Systolic and diastolic blood pressure by non-invasive method, pulse rate and $\mathrm{SpO} 2$ through pulse oximetry was recorded every 10 minutes in the operating room and every 30 minutes thereafter. Episodes of perioperative hypotension (Mean arterial pressure $<70 \mathrm{mmHg}$ ), bradycardia (heart rate $<50$ beats per minute) and desaturation (SpO2 < 90\%) were recorded.

\section{Sedation}

Level was assessed every 10 minutes intraoperatively and every 30 minutes in the postoperative room using Brain Ready Sedation Score. Side effects such as nausea and vomiting, pruritus were observed. Intraoperative as well as postoperative incidences of shivering were recorded.

\section{Shivering}

Incidence of shivering was recorded intraoperatively. Shivering was graded as (Mao CC et al). None: No perceptible tension of muscles observed; Mild: Slight muscle tonus (masseter muscle); Moderate: Real shivering (proximal muscles); Severe: Generalised shivering (whole body).

Datas were analysed using one-way analysis of variance. $P$ value of $<0.05$ was considered statistically significant. Datas are presented as mean $+\mathrm{SD}$, mean values (ranges) and percentages.

\section{RESULTS}

\begin{tabular}{|c|c|c|}
\hline Groups & Dermatomal & Mean \pm SD \\
\hline B & T5 $-\mathrm{T} 9$ & $7.3 \pm 0.96$ \\
\hline FB & T4 - T9 & $5.9 \pm 1.01$ \\
\hline CB & T4 - T9 & $6.7 \pm 1.26$ \\
\hline CFB & T4 - T9 & $5.7 \pm 1.11$ \\
\hline \multicolumn{2}{|c|}{ Table 1. Highest Dermatomal Levels } \\
\hline
\end{tabular}

$P$ - value $<0.05$.

\begin{tabular}{|c|c|c|}
\hline Groups & $\begin{array}{c}\text { Time for Highest } \\
\text { Dermatomal Level (Mins.) }\end{array}$ & $\begin{array}{c}\text { Mean } \pm \text { SD } \\
\text { (Mins.) }\end{array}$ \\
\hline B & $5-10$ & $6.9 \pm 1.2$ \\
\hline FB & $4.5-9$ & $6.4 \pm 1.2$ \\
\hline CB & $4.5-9$ & $6.9 \pm 1.3$ \\
\hline CFB & $4-8$ & $6.2 \pm 1.2$ \\
\hline \multicolumn{2}{|c|}{ Table 2. Time for Highest Dermatomal Level (Mins.) } \\
\hline
\end{tabular}

$\mathrm{P}$ value $>0.05$

\begin{tabular}{|c|c|c|}
\hline Groups & $\begin{array}{c}\text { Time for 2-Segments } \\
\text { Regression (Mins.) }\end{array}$ & $\begin{array}{c}\text { Mean } \pm \text { SD } \\
\text { (Mins.) }\end{array}$ \\
\hline B & $58-93$ & $71.9 \pm 9.2$ \\
\hline FB & $68-122$ & $94.8 \pm 14.2$ \\
\hline CB & $67-144$ & $93.6 \pm 11.0$ \\
\hline CFB & $66-140$ & $102.5 \pm 14.9$ \\
\hline Table 3. Time for 2-Segments Regression (Mins.) \\
\hline
\end{tabular}

$\mathrm{P}$ - value $>0.05$.

\begin{tabular}{|c|c|c|}
\hline Groups & $\begin{array}{c}\text { Onset of Grade 3 Motor } \\
\text { Blockade (Mins.) }\end{array}$ & $\begin{array}{c}\text { Mean } \pm \text { SD } \\
\text { (Mins.) }\end{array}$ \\
\hline B & $4-10$ & $7.1 \pm 1.4$ \\
\hline FB & $4-8$ & $6.4 \pm 1.1$ \\
\hline CB & $5-9$ & $6.7 \pm 1.1$ \\
\hline CFB & $4.5-9$ & $6.4 \pm 1.1$ \\
\hline \multicolumn{2}{|c|}{ Table 4. Onset of Grade 3 Motor Blockade (Mins.) } \\
\hline
\end{tabular}

$\mathrm{P}$ - value $<0.05$. 


\begin{tabular}{|c|c|c|}
\hline Groups & $\begin{array}{c}\text { Duration of Grade 3 } \\
\text { Motor Blockade (Mins.) }\end{array}$ & $\begin{array}{c}\text { Mean } \pm \text { SD } \\
\text { (Mins.) }\end{array}$ \\
\hline B & $66-118$ & $96.5 \pm 13.2$ \\
\hline FB & $85-135$ & $109 \pm 20.0$ \\
\hline CB & $95-185$ & $122.8 \pm 21.3$ \\
\hline CFB & $95-174.5$ & $125.4 \pm 18.7$ \\
\hline \multicolumn{2}{|c|}{ Table 5. Duration of Grade 3 Motor Blockade (Mins.) } \\
\hline
\end{tabular}

$P$ - value $>0.05$

\begin{tabular}{|c|c|c|}
\hline Groups & $\begin{array}{c}\text { Duration of Absolute } \\
\text { Pain Free Period VAPS }= \\
\text { 0 - 1 (Mins.) }\end{array}$ & $\begin{array}{c}\text { Mean } \\
\text { (Mins.) }\end{array}$ \\
\hline B & $115-168$ & $138.5 \pm 16.5$ \\
\hline FB & $163-284$ & $206.3 \pm 45.0$ \\
\hline CB & $140-315$ & $214.9 \pm 42.4$ \\
\hline CFB & $223-373$ & $294 \pm 33.7$ \\
\hline \multicolumn{3}{|c|}{ Table 6. Duration of Absolute } \\
Pain Free Period VAPS = 0 - 1 (Mins.) \\
\hline
\end{tabular}

$P$ - value $>0.05$

\begin{tabular}{|c|c|c|}
\hline Groups & $\begin{array}{c}\text { Total Duration of } \\
\text { Analgesia VAPS }=5 \text { or } \\
\text { More (Mins.) }\end{array}$ & $\begin{array}{c}\text { Mean } \\
\text { (Mins.) }\end{array}$ \\
\hline B & $152-223$ & $184.9 \pm 18.1$ \\
\hline FB & $215-359$ & $274.5 \pm 28.3$ \\
\hline CB & $180-378$ & $274 \pm 40.4$ \\
\hline CFB & $268-423$ & $357.1 \pm 35.4$ \\
\hline \multicolumn{3}{|c|}{ Table 7. Total Duration of } \\
Analgesia VAPS $=5$ or More (Mins.) \\
\hline
\end{tabular}

$P$ - value $>0.05$

\begin{tabular}{|c|c|c|c|c|}
\hline Groups & $\begin{array}{c}\text { Hypotension } \\
\text { (No. of } \\
\text { Patients) }\end{array}$ & $\begin{array}{c}\text { Nausea } \\
\text { and } \\
\text { Vomiting }\end{array}$ & Pruritus & Shivering \\
\hline B & 2 & - & - & 5 \\
\hline FB & 3 & 3 & 2 & 4 \\
\hline CB & 5 & - & - & - \\
\hline CFB & 7 & 4 & 3 & - \\
\hline \multicolumn{5}{|c|}{ Table 8. Complications } \\
\hline
\end{tabular}

\section{DISCUSSION}

Prolongation of the local anaesthetic blockade has been attributed to localised vasoconstriction, thereby decreasing the uptake of local anaesthetics from the spinal subarachnoid space. ${ }^{1}$ (Maddi R, Francis D et al) Recent studies evaluate the role of Alpha 2 -adrenergic agonist in modulating neural pathways and demonstrate that these drugs inhibit in vitro nerve conduction in $\mathrm{A}$ and $\mathrm{C}$ fibres. Clonidine enhances the effects of lidocaine on C-fibre action potential. Clonidine is also effective after oral administration reaching a peak plasma concentration within 60 - 90 mins. When administered as a pre-anaesthetic medication clonidine provides preoperative sedation, greater intraoperative haemodynamic stability and a reduction in the anaesthetic and postoperative analgesic requirements. Prolongation of local anaesthetic-induced spinal sensory and motor block is well documented after coadministration with intrathecal-clonidine ${ }^{2}$ and also by orally clonidine 60 - 90 minutes before subarachnoid block with local anaesthetics (Bonnet $\mathrm{F}$ et $\mathrm{al}$ ).

Postoperative pain relief following intrathecal bupivacaine was prolonged by both oral clonidine as well as intrathecal clonidine. ${ }^{3}$ (Dobrydnjov I Axelsson $\mathrm{K}$ et al). Oral clonidine attains a peak plasma concentration 60 - 90 minutes after administration has potent antinociceptive action through Alpha2 receptor mediated mechanism in the dorsal horn of spinal cord and blocks the conduction in $\mathrm{A} \infty$ and $\mathrm{C}$ fibres.

Hunt Co, Naulty et al, intrathecal fentanyl has also been reported to improve intraoperative analgesia and to prolong the duration of bupivacaine induced spinal block. ${ }^{4}$ Wang $\mathrm{C}$, Chakrabarti MK, Whitwam JG. Recently, studies ${ }^{5}$ also demonstrated that intrathecal fentanyl acts synergistically to enhance the effect of bupivacaine on afferent nociceptive pathways in dogs.

The combination of clonidine with fentanyl increased the intraoperative analgesic efficacy and significantly prolonged postoperative analgesia compared with clonidine alone. Experimental studies have shown that synergism can be demonstrated between intrathecal opioids and alpha 2 agonist. Highest dermatomal levels achieved was significantly different from Groups B and FB, Group B and CFB (P value $<0.05$ ). So with fentanyl added to with bupivacaine, the dermatomal level after intrathecal injection was found to be higher. There was no significant difference between Groups B and CB. No significant spread of sensory block was observed in oral clonidine with bupivacaine group. The high dermatomal level in CFB was attributable to the fentanyl.

The two-segment regression time was significantly different between Groups B and CFB, CB and CFB. B and FB, B and $C B(P$ value $<0.05)$. No significant difference between Groups FB $(94.8 \pm 14.2)$ and CB $(93.6 \pm 11.6)$. The two-segment regression time was prolonged significantly both in fentanyl with bupivacaine and clonidine with bupivacaine. If both added together as in CFB, the regression time was still more prolonged $102.5 \pm 14.9$ mins. The results of this study correlates well with a similar study reported by(3) (Dobrydnjov I and Axelsson) that the two-segment regression time was significantly longer in the clonidine group.

Significant difference among groups in duration of Grade 3 motor blockade ( $\mathrm{P}$ value of $<0.05$ ). The duration of motor blockade was significantly prolonged in clonidine premedicated Groups ( $\mathrm{CB}$ and $\mathrm{CFB}$ ). The results are wellcorrelated with similar study(6) Harbhej Singh et al. He had demonstrated that oral clonidine prolonged the duration of Grade 3 motor blockade of spinal tetracaine and also oral clonidine prolonged the duration of motor block by lidocaine, 7 Liu S and Chiu et al.

There was significant difference $(\mathrm{P}<0.05)$ in the duration of absolute pain free period between Groups FB, $206.3 \pm 45$ mins. and CB $214.9 \pm 42.4$ mins.

There was significant difference in total duration of analgesia between groups except between Groups FB and CB ( $P$ value of $<0.05$ ). The duration was almost similar in both FB and CB Groups. The duration is very significantly prolonged in Group CFB. Similar studies about postoperative pain relief following intrathecal bupivacaine $(15 \mathrm{mg})$ combined with oral clonidine $(150 \mu \mathrm{g})$ and observed that oral clonidine prolonged the time until the first request for analgesics, $313 \pm 29$ mins. versus $236 \pm 27$ mins. in bupivacaine-only group. No shivering was seen in clonidine premedicated patients, ${ }^{8}$ Mao CC et al.

\section{CONCLUSION}

This study demonstrates that oral clonidine premedication prolonged the duration of sensory and motor blockade of 


\section{Jemds.com}

intrathecal bupivacaine. Intrathecal fentanyl itself prolonged the sensory blockade of bupivacaine. The combination of oral clonidine and intrathecal fentanyl with bupivacaine increased the intraoperative analgesia efficacy and significantly prolonged postoperative analgesia compared with either clonidine or fentanyl alone. However, this combination was associated with slightly increased incidence of bradycardia and hypotension which were easily treatable and moderately increased sedation, which can be considered an advantageous side effects because it allows a calm intraoperative course.

\section{REFERENCES}

1. Meddi R, Concepcion M, Francis D, et al. Vasoconstrictors in spinal anesthesia with tetracaine a comparison of epinephrine and phenylephrine. Anaesthesia Analgesia 1984;63(2):134-8.

2. Bonnet F, Buisson VB, Francois Y, et al. Effects of oral and subarchnoid clonidine on spinal anaesthesia with bupivacaine. Regional Anaesthesia 1990;15(4):211-4.

3. Dobrydnjov I, Axelsson $\mathrm{K}$, Holmstrom $\mathrm{B}$, et al. Postoperative pain relief following intrathecal bupivacaine combined with intrathecal or oral clonidine. Acta Anaesthesiol Scand 2002;46(7):806-14.

\section{Original Research Article}

4. Hunt CO, Naulty JS, Bader AM, et al. Perioperative analgesia with subarachnoid fentanyl-bupivaine for caesarean delivery. Anaesthesiology 1989;71(4):535-40.

5. Wang C, Chakrabarti MK, Whitwam JG. Specific enhancement by fentanyl of the effects of intrathecal bupivacaine on nociceptive afferents but not on sympathetic efferent pathways in dogs. Anaesthesiology 1993;79(4):766-73.

6. Harbhej Singh H, Liu J, Gaines GY, et al. Effect of oral clonidine and intrathecal fentanyl on tetracaine spinal block. Anaesthesia Analgesia 1994;79(6):1113-6.

7. Liu S, Chiu AA, Neal JM, et al. Oral clonidine prolongs lidocaine spinal anaesthesia in human volunteers. Anaesthesiology 1995;82(6):1353-9.

8. Mao CC, Tsou MY, Chia YY, et al. Pre-anaesthetic oral clonidine is effective to prevent post-spinal shivering. Acta Anaesthesiol Sin 1998;36(3):137-42. 